\title{
Cross-National Differences in the Association Between Parental Work Hours and Time with Children in Europe: A Multilevel Analysis
}

\author{
Anne Roeters
}

Accepted: 3 October 2011/Published online: 14 October 2011

(C) The Author(s) 2011. This article is published with open access at Springerlink.com

\begin{abstract}
This study investigates cross-national differences in the association between parental work hours and parent-child interaction time and explains differences in this individual-level association on the basis of country characteristics. It extends prior research by testing the moderating effects of country characteristics through multilevel analyses and by considering the possibility of selection effects. The presumption was that parents employ strategies to protect family life from work encroachments and that these strategies are enhanced by reconciliation policies, stronger parenthood ideologies, access to part-time work and higher income levels. Multilevel analyses were based on a subset of 5.183 parents in 23 countries from the 2005 European Working Conditions Survey that was complemented with country-level data. The negative association between parental work hours and parent-child time indeed varied significantly across countries and was weaker in countries where formal child care coverage was higher, part-time work was less prevalent, and earnings were lower. The effects of part-time work and earnings mainly applied to mothers. These findings suggest that child care coverage limits the availability of children and that differences in parent-child time between parents who work short and long hours are more pronounced when part-time work is more accessible and affordable.
\end{abstract}

Keywords Cross-national comparison - Multilevel analysis · Parent-child time · Parental work $\cdot$ Part-time work $\cdot$ Reconciliation policies

\section{Introduction}

In 2007, UNICEF presented a comparative study on child well-being in Western industrialized countries and concluded that children are best off in Northern European countries, in part because parents in these countries spend a relatively large amount of time with their children (UNICEF 2007). The Northern European countries are also the countries where

\footnotetext{
A. Roeters $(\bowtie)$

Department of Sociology/Interuniversity Centre for Social Science Theory and Methodology (ICS), Utrecht University, Heidelberglaan 2, 3584 CS Utrecht, The Netherlands

e-mail: a.roeters@uu.nl
} 
parents spend a great deal of their time on the labor market (Esping-Andersen 1999) and these findings therefore challenge the widespread belief that paid work restricts parents in spending time with their children (e.g., Bianchi 2000; Bianchi, Robinson and Milkie 2006; "Female Power," 2010; Nuffield Foundation 2009). The current study examines parents' opportunities to limit work encroachments by studying whether the association between paid work hours and parent-child time is conditioned by the country context. Do European countries differ with regard to the association between parental work hours and the time parents spend with children? And if so, do cross-national differences in family policies and norms, that affect parents' opportunities to protect family life, account for these differences?

Recently, Sayer and Gornick (forthcoming) examined and explained cross-national variations in the association between work hours and parent-child time in nine countries. The study is largely descriptive in nature and offers interesting insights in cross-national differences. For example, the authors found that the association between work hours and parent-child time was strongest in the English-speaking countries and state that "this pattern suggests that a combination of strong regulations on work hours and policies that facilitate parents' ability to combine employment and child care buffer the downward pressure of employment hours on child care time" (p. 17). Despite the plausibility of their explanations Sayer and Gornick base their interpretations on a discussion of country differences and similarities and not on statistical tests that can be obtained through multilevel analysis. The current study re-examines the question how the association between work hours and parent-child varies, but, in contrast to Sayer and Gornick, uses multilevel analyses with cross-level interactions to test which country characteristics affect this association.

The current paper adds to the literature in a second way. When studying the association between work hours and parent-child time, selection effects are an important issue, especially in cross-national studies. The extent to which parents can choose their own work hours is a central dimension of work-family policies that varies between countries. For example, in the Netherlands, employees have the right to reduce their work hours and many women with children do so, whereas this is not the case in, for example France (Plantenga and Remery 2005). Traditionally, the cross-national work-family literature assumes that family supportive policies buffer work encroachements for individual families (Moen and Wethington 1992; Sayer and Gornick, forthcoming). Yet, the varying likelihood of selection effects implies that country differences in the association between work hours and parent-child time might also reflect differences between groups of parents. For example, if in the Netherlands, highly involved parents can easily select themselves into part-time jobs, whereas in France they cannot, we cannot exclude the possibility that work hours and parent-child are less strongly related in France because the highly involved parents are forced to work long hours and compensate for their absence by maximizing the time with their children in other ways (e.g., by giving up sports). Gauthier et al. (2004) applied a similar line of reasoning when they explained the increasing divergence in mother-child time between employed and non-employed mothers from 1960 to 2000.

The current study analyses multilevel models with cross-level interaction effects to examine which country characteristics moderate the individual-level association between work hours and parent-child time. I consider three types of country characteristics. First, work and family demands may more easily be combined in countries and welfare states where parents receive more government support through reconciliation policies, such as leave arrangements and child care (Den Dulk and Van Doorne-Huiskens 2007; EspingAndersen 1999; Gornick and Meyers 2003; Plantenga and Remery 2005; Sayer et al. 
2004). Second, cultural norms may have implications for the extent to which parents (are allowed to) let work intrude upon parent-child time. The third type of country characteristic relates to the possible selection effect. I will argue that parents can more easily reduce their work hours when institutional and financial restrictions are lower and parttime work is more widely accessible. The current study extends prior research on the impact of work on parent-child time by investigating whether country-level policies, earnings, and social norms are relevant for employed parents in the sense that they increase or reduce the association between parental work hours and parent-child time. I investigate this issue by employing multilevel models with cross-level interactions based on data from the European Working Conditions Survey (EWCS) 2005 on 23 European countries.

Family life can benefit, as well as suffer, from parental employment (Greenhaus and Powell 2006; Roeters et al. 2010), but I focus on work demands, and work hours in particular, because these are the most commonly considered work-related antecedent of parent-child time. Moreover, although it is likely that work-family strategies are determined on the couple level as well as on the individual level (e.g., Bianchi 2000; Coverman 1985; Nock and Kingston 1988; Presser 1994), I will look at individual parents. Studying cross-national differences in the association between work hours and parent-child time among individual parents is a first step in exploring work-family strategies. Also, despite some exceptions, such as the French time use data (Lesnard 2008), couple data are rare, which makes it difficult to draw a cross-national comparison.

\section{Previous Research}

Cross-national differences in the time parents spend with their children have mostly been considered in the framework of studies on trends in parent-child time. Sayer et al. (2004) compared Canada, Germany, Italy, and Norway in the late 1980s and early 1990s, and Gauthier et al. (2004) covered sixteen industrialized countries between the 1970s and 2000. Because the main focus of these studies was on trends over time, the authors did not analyze the underlying patterns. Cross-national differences in the association between work hours and parent-child time have been addressed by only a limited number of studies thus far. Stone (1972) compared twelve Western countries and found that the effects of maternal employment on mother-child time were particularly strong in France and the U.S. Also, Bianchi et al. (2006) found that the effect of women's employment status was slightly weaker in the Netherlands and France than in the U.S., Canada, and the U.K. Neither of these studies provided an explanation for the cross-national differences that were found.

Sayer and Gornick (forthcoming) made a more extensive effort to explain cross-national variations in the association between work hours and parent-child time, focusing on the interplay of employment regulations, family policies and gender relations. The authors theorized that the impact of work hours on parent-child time would be weakest in countries where parents had more time available as the result of strict work hour limits and generous family policies, and cultural norms prescribed parents to take up the care for their children themselves instead of making use of available formal child care. Using time use data on nine countries, predicted means of weekly parent-child time for five different employment hour categories were estimated and compared across countries (within employment hour categories) and employment hour categories (within countries). The general pattern that emerged from these comparisons indicated that the negative association between work hours and parent-child time was strongest for parents in the Anglo-Saxon countries, 
weaker for mothers in Norway, Sweden, and France, and nonsignificant for Dutch parents and Norwegian, Swedish, and French fathers. After linking differences in the effects of work hours to differences in the countries' employment regulations, family policies, and gender relations, Sayer and Gornick concluded that the negative impact of work hours was buffered by the specific combination of strict work hour regulations and the availability of reconciliation policies.

Although Sayer and Gornick claim that it is the interplay of policies and norms that matters and that it is therefore not their intention to test direct policy effects, the complexity of their analysis and interpretation does trigger the question exactly which (combinations of) policies and regulations matter and whether alternative explanations can be ruled out (e.g., the Anglo-Saxon countries differ from the other countries in terms of culture and affluence as well). The value of using multilevel analyses to test the moderating effects of country-level characteristics has been demonstrated by other cross-national studies. For example, Hook (2006) tested whether country characteristics conditioned the effects of family demands on men's unpaid work (including, but not limited to, child care) and demonstrated that men's unpaid work was more responsive to family demands in countries where mothers worked longer hours and fathers had better access to parental leave arrangements. Moreover, Fuwa (2004) hypothesized that inequalities on the macrolevel would counteract the effects of micro-level power benefits of women and indeed found that women's time availability had a weaker impact on the division of household labor in countries that were less gender-egalitarian.

\section{Theoretical Framework}

\subsection{Individual Level Base Hypothesis}

The starting point of the theoretical framework is a base hypothesis on the individual level: the longer a parent's paid work hours, the less time this parent spends with his or her children (Base Hypothesis). Research on the individual level generally depicts time as a fixed resource that has to be divided between paid work and the family: longer work hours therefore reduce a parent's time availability (e.g., Coverman 1985; Eby et al. 2005; Greenhaus and Beutell 1985; Sayer and Gornick forthcoming). Although empirical studies showed that paid work only has a minimal effect on parent-child time (e.g., Bianchi 2000; Bianchi et al. 2006; Crouter et al. 2001; Gauthier et al. 2004; Nock and Kingston 1988), the 'fixed pie' approach remains the dominant framework in the literature and therefore offers a suitable starting base for the hypotheses on the country characteristics.

Some scholars argued that parents do not react passively to the demands that are imposed on them, but act strategically instead and find different ways to limit detrimental influences from other domains such as the work domain (Bianchi 2000; Becker and Moen 1999; England and Farkas 1986; Moen and Wethington 1992). For example, parents can leave work early to pick up their children from school and finish work in the evening or they can reduce their work hours altogether. Such 'family adaptive' (Moen and Wethington 1992) or 'work-family strategies' (Becker and Moen 1999) minimize the extent to which work hours cut into parent-child time as they enable parents to combine their family responsibilities with their role as an employee (Bianchi et al. 2006).

If parents indeed maximize parent-child time, the extent to which the base hypothesis holds is likely to depend on the parents' opportunities to employ work-family strategies. I examine two types of work-family strategies that emerge from the literature: Parents can 
either take an effort to reconcile high work and high family demands or they can reduce their work demands (Becker and Moen 1999; Bianchi et al. 2006: 86; Casper and Bianchi 2002; Gauthier et al. 2004; Moen and Wethington 1992). Below, I formulate hypotheses on the specific country characteristics that can facilitate or restrict the use of these strategies.

\subsection{Opportunities to Reconcile Work and Family Demands}

The 'fixed pie' assumption that work hours cut directly into parent-child time does not take into account how work and family demands are organized and planned. When parents can fine-tune their work and family responsibilities, work encroachments can be limited (Becker and Moen 1999; Bittman 2009). Job flexibility permits parents to arrange work and family life in a way that is most efficient and favorable considering their specific circumstances. For example, flexible work arrangements allow parents to work when children are not available (because they are in school, involved in extra-curricular activities, or sleeping) and be at home when the children are. This decision latitude allows parents to protect and attend to family responsibilities, even when they work long hours. The extent to which parents have the opportunity to reconcile work and family responsibilities is likely to depend on two country-level factors: the availability of reconciliation policies and cultural norms regarding work and children.

First, reconciliation policies are likely to create a buffer for negative work-to-home interference because they provide working parents with flexibility. Or, as Sayer et al. (2004) stated: "Family policies and programs (...) may provide more degrees of freedom to all parents in making decisions about time allocation" (p. 1,153, emphasis by the author). Prior research indicated that Northern European, Social Democratic countries offer a wider range of reconciliation policies than Continental, Anglo-Saxon and Southern European countries (e.g., Esping-Andersen 1999; Gornick and Meyers 2003; Hook 2006; Organization for Economic Coorperation and Development [OECD] 2007; Plantenga and Remery 2005; Poelmans and Caligiuri 2008; Sayer et al. 2004; Sayer and Gornick forthcoming). This suggests that parents in Northern European countries have more opportunities to reconcile high work and family demands. Social policies also set a moral example, influencing the extent to which it is socially accepted to prioritize one's family at work and, for example, go home when a child is sick. The first hypothesis therefore reads as follows: the negative association between parental work hours and parent-child time is weaker in countries with more reconciliation policies (Hypothesis 1). Within the range of reconciliation policies, child care coverage is a specific case. It's use will not increase parent-child time as it is a substitute for parental care and therefore it cannot be used to maximize parent-child time as the other policies can. Yet, paid work hours are less likely to cut into parent-child time when children are in child care and thus unavailable (Bianchi 2000; Sayer and Gornick forthcoming). I therefore specifically examine the effect of child care coverage.

Second, the association between work hours and parent-child time may be conditioned by cultural norms. Protecting family life from the demands of work requires effort and making difficult choices (Bianchi et al. 2006). Whether or not parents do so and (potentially) sacrifice either work success or individual well-being, may depend on the presence of cultural norms advocating the protection of the family. If the parenthood ideology in a country calls on parents to heavily invest in their children's development, parents will be more reluctant to let their work hours affect the time they spend with their children and instead cut down on activities that are not child-related such as couple activities, "adultonly" leisure, personal care and community time (Bianchi et al. 2006; Hays 1996; 
Mattingly and Bianchi 2003). Such norms will therefore increase the inelasticity of the association between work hours and parent-child time. In other words, strong parenthood norms may 'force' parents into family protective strategies and limit their opportunities to let work intrude upon family life. Norms regarding parenthood can either be internalized (e.g., a mother feeling guilty when she has to work late) or have an external influence (e.g., friends or family criticizing a mother for working full-time).

The ways in which children and gender roles are regarded are a central part of a country's cultural profile (Wall 2007). Countries differ in their norms towards parenthood and paid work and whereas maternal employment is considered harmful in, for example, the Netherlands, children are considered deprived when they do not go to day care in, for example, Sweden (e.g., Jones and Brayfield 1997; Treas and Widmer 2000; Wall 2007). Moreover, children are viewed as more essential to an individual's life in Southern European countries than in Northern European countries (Jones and Brayfield 1997). I consider the parenthood ideology of a country to be stronger when attitudes towards maternal employment are more conservative and children are viewed as more central and hypothesize that the negative association between parental work hours and parent-child time is weaker in countries with stronger parenthood ideologies (Hypothesis 2).

\subsection{Opportunities to Reduce Work Hours}

Instead of finding ways to reconcile high work and family demands, parents may decide to work fewer hours in order to free time for their children (Becker and Moen 1999). The extent to which parents have the opportunity to reduce their hours depends, among other things, upon the country in which they live. In countries that allow parents to select their own work hours, parents who want to be strongly involved in the upbringing of their children can choose to work part-time and thereby free time for their children. Under these same conditions, parents who have a stronger focus on their work and are less familyoriented (Hakim 2002) will more likely choose to work full-time. By implication, these two groups of parents will differ substantially with regard to the time they spend with their children.

When a country does not offer parents the opportunity to choose their work hours, the family- and work-oriented parents will be distributed over part-time and full-time jobs relatively at random. In these countries external factors such as economic circumstances and the specific education of a parent will be more decisive for their work hours than their own preferences (e.g., Reynolds 2003). As a result, child-oriented parents who work fulltime are likely to compensate for their absence and find other ways to minimize the impact of work, for example by economizing on the time they spend in leisure activities or personal care. Similarly, parents who are less child-oriented and work part-time will be more likely to allocate the additional time they have available to activities that are not child-related, such as community work. As a consequence, the difference in parent-child time between parents who work a low and a high number of hours will be relatively small in these countries as compared to countries with a higher decision latitude. The basic argument that the context affects between-group differences was based on an idea by Gauthier et al. (2004). In their longitudinal study they found that differences in motherchild time between employed and nonemployed mothers increased between 1960 and 2000 and explained this on the basis of mothers' increased decision latitude regarding their employment status.

I expect that the extent to which parents who want to spend a lot of time with their children have the opportunity to work part-time depends upon two country characteristics. 
First, policies regarding work hours should allow parents to scale back in their hours (e.g., Plantenga and Remery 2005). Second, working part-time has to be financially possible and the parents' earnings should be sufficient to provide for the family needs. I therefore assume that when the policy context and financial conditions are favorable, strongly childoriented parents will choose to work less hours jobs, whereas the less strongly childoriented parents will choose to work full- time. Because this results in two heterogeneous groups of parents the difference in parent-child time between these two groups will be large as compared to countries where parents are restricted in reducing their hours. It is difficult to assess access to part-time work directly, so I assume that this is reflected in the prevalence of part-time work. This also implies that I assume that people work part-time because they choose to, and not because they are forced into such an arrangement. Summarizing, I expect that the the negative association between parental work hours and parent-child time is stronger in countries with a higher prevalence of part-time work (Hypothesis 3) and in countries with higher earnings (Hypothesis 4).

\section{Method}

\subsection{Data, Sample, and Response}

The European Working Conditions Survey (EWCS) is an European Union funded project that is coordinated by the European Foundation for the Improvement of Living and Working Conditions (Eurofound). The aim of the survey is to provide insight into the working conditions of European countries and to provide input for the creation of social policy (Eurofound 2007b). I used the 2005 wave that covered 31 countries: the EU27 countries, plus the two candidate countries, Turkey and Croatia, and Norway and Switzerland. The fieldwork was carried out in the autumn of 2005 (Eurofound 2007b). The large number of countries that is covered by the EWCS is an advantage over other data sets, such as the Multinational Time Use Survey (MTUS) (e.g., Hook 2006). Although the MTUS data include 20 countries, data after 1995 are available for only five of these countries. Because the objective of this study is to gain further insight in the work-family balance of modern-day families, I decided to use the EWCS data instead.

The EWCS data set is representative of all European persons aged 15 or older in paid employment (Eurofound 2007b). A person was considered to be employed if "he or she did any work for pay or profit during the reference week for at least 1 hour" (Eurofound 2007b: 7). The sample was collected using a multiple stage design and was representative with regard to the regions and urbanization level. In most countries the households were selected through the "random walk" procedure, with the exception of Belgium, Sweden, Netherlands, and Switzerland where respondents were selected through phone screening. The samples in these countries are nonetheless stratified according to the region and urbanization level (Eurofound 2007b). The data were collected through face-to-face interviews, held at the respondents' homes. A total of 72,300 households were visited and 29,680 interviews were administered. The overall response rate (defined as the proportion of completed interviews to the total number of eligible cases) was $48 \%$. The country-level response rates varied between $28 \%$ in the Netherlands and $67 \%$ in Turkey (Eurofound 2007b: 28).

For this specific study a sub-sample was selected: Those respondents who had at least one minor child living in the same household, did not have a missing value on the work hours variable, and spent time with their children everyday for at least one hour. This 
implies that our sample covers employed parents whose involvement was relatively high. The rationale for this last criterion will be addressed below. Also, data on one or more country-level variables were not available for eight of the 31 countries. These countries were excluded, leaving the EU25 countries minus Cyprus and Malta. ${ }^{1}$ The final sample size on the individual level was 5,183.

\subsection{Measures}

\subsubsection{Dependent Variable: Daily Parent-Child Time}

The 2005 wave of the EWCS included two questions on parental involvement with their children. First, the respondents were asked how often they were involved in caring for and educating their children. The answer categories were $1=$ everyday for $1 \mathrm{~h}$ or more, $2=$ everyday or every second day for less that $1 \mathrm{~h}, 3=$ once or twice a week, $4=$ once or twice a month, $5=$ once or twice a year, and $6=$ never. Second, the respondents who answered "everyday for $1 \mathrm{~h}$ or more" were presented with an additional open question asking them for how many hours per day they were involved. This number was taken as the final measure for the amount of parent-child time because this measure contained most variation. This did imply that the respondents that indicated spending less than an hour with their children (30\% of the full sample) were excluded and that the proportion of women in the final sample is relatively high (64\%). Additional analyses were performed to check whether basing the dependent variable on the interval variable with the restricted sample, instead of on the categorical variable with the broader sample had consequences for the results, but the differences were small. Extreme values of $17 \mathrm{~h}$ and more were rounded off to $16 \mathrm{~h}$ (it is unlikely that children are awake during all these hours), which resulted in a final measure for the parent's daily involvement with answers ranging from 1 to $16 \mathrm{~h}$. Because the dependent variable was skewed to the right, I ran additional models to check the robustness of the results.

\subsubsection{Individual-Level Predictors}

The respondents were asked how many hours they usually worked per week in their main paid job and (when applicable and structural) second job. From these values a single value for the respondent's weekly paid work hours was constructed. The models controlled for a number of family characteristics that are commonly considered in the literature. The family demands, that are likely to increase parent-child time (e.g., Coverman 1985), were taken into account by including the age of the youngest child and the number of minor children in the household in the model. Moreover, we controlled for the respondent's gender $(1=$ female, $0=$ male $)$, as women participate more in child care than men, and for the respondent's educational level because previous research consistently showed that parental involvement is higher among higher educated parents (e.g., Craig 2007; Sayer et al. 2004). The educational level was coded according to the ISCED classification and varied from 0 to 16. Mean imputation was used for the twelve respondents who had a missing value on the education variable.

\footnotetext{
1 The countries included in the study are: Austria, Belgium, the Czech Republic, Denmark, Estonia, Finland, France, Germany, Greece, Hungary, Ireland, Italy, Latvia, Lithuania, Luxembourg, the Netherlands, Poland, Portugal, Slovakia, Slovenia, Spain, Sweden, and the UK.
} 


\subsubsection{Country-Level Variables}

Hypotheses 1 and 2 on the reconciliation of work hours and parent- child time were tested using three indicators: government support for working families, child care coverage and child-related norms. The indicator used to measure government support for working families was the public spending on families as a percentage of GDP in 2005 (OECD Family Database 2008). This included public spending on family benefits in cash, services, and tax measures. In order to separate the effects of the provision of formal child care, an additional measure for child care coverage was included. This measure was based on EU data on the percentages of pre-school-age children that were in formal child care for $30 \mathrm{~h}$ or more per usual week in 2006 (Commission of the European Communities 2008: 4). This is a strict measure as it concerns substantial coverage. The data distinguished between child care coverage for children up to 3 years and aged three through the mandatory school age and the average score over these two values was taken. The variable measuring the strength of a country's parenthood ideology was based on data from the World Values Survey (World Values Survey Association 2000) that was accessed though the online database. The data from the 1999 wave were used because this wave preceded the collection of the EWCS data in 2005 and because the data were complete for this year. The final measure was constructed in two steps. First, two separate scales were constructed for the centrality of children and disapproval of maternal employment. The former scale was based on four items (Cronbach's $\alpha$ : .63, e.g., "Parents duty is to do their best for their children even at the expense of their own well-being") and the latter scale was based on two items ( $\alpha$ : .75, e.g., "A pre-school child is likely to suffer if his or her mother works"). For each item, answer categories ranged from $1=$ strongly disagree through $5=$ strongly agree. Second, I took the percentage in each country that (strongly) agreed or disagreed in such a way that higher scores indicated a stronger parenthood ideology. The final measure consisted of the average over the two scales in order to let the measure reflect general attitudes towards children and attitudes towards employment and children equally (the $\alpha$ over all items is .70).

Hypotheses 3 and 4 were tested on the basis of two country-level variables: The prevalence of part-time work and hourly earnings. The percentage of the workforce working in part-time employment in 2005 was based on data from Eurofound (2007a: 4). In order to measure to what extent parents need a double fulltime income to fulfill family needs the average hourly earnings in Power Purchasing Standards (PPS) of the lowest income decile in 2002 was included. PPS is an artificial currency unit that takes differences in national price levels into account. The final measure was constructed by dividing the average gross annual earnings in PPS (Eurostat 2006: 3) by the county's average number of work hours (as calculated on the basis of the EWCS data). The earnings of the lowest income decile were selected as opposed to the earnings of the general population, because it reflects the minimum income level and is not distorted by any possible large income inequalities in a country. All variables, with the exception of the hourly earners, were recorded into proportions in order to make interpretation easier. Moreover, the individuallevel variables (with the exception of gender) were grand-mean centered and the countrylevel variables were centered around the average across the countries.

\subsection{Analytical Strategy}

Because the respondents were nested in countries, multilevel analysis was employed using the statistical software package MLwiN 2.10. The hypotheses were tested using cross-level 
Table 1 Descriptive statistics of the individual-level variables

\begin{tabular}{lcccc}
\hline & M & SD & N & Range \\
\hline Parent-child time & 3.93 & 3.07 & 5.183 & $1-16$ \\
Female $(0=$ yes $)$ & 0.64 & 0.48 & 5.183 & $0-1$ \\
Age youngest child & 7.48 & 4.78 & 5.183 & $0-17$ \\
Number of children & 1.72 & 0.80 & 5.183 & $1-8$ \\
Educational level & 3.48 & 1.24 & 5.171 & $0-6$ \\
Paid work hours & 38.19 & 12.37 & 5.183 & $1-120$ \\
\hline
\end{tabular}

Source: EWCS 2005

interactions. Although the theoretical framework focused on the moderating effects of country characteristics, the direct effects were also be examined. Unfortunately the scope of this study did not allow taking the direct effects of country-level characteristics on the individual work hours into account as well. A total of ten models were estimated. ${ }^{2}$ In the first two steps (results not reported in a table) the intercept-only model was tested and the individual-level predictors were entered. In the third step the coefficient of work hours was allowed to vary between the countries (Model 1). Because the sample-size did not allow me to enter all five country-level variables in the same model, Hypotheses 1 and 2 were tested separately from Hypotheses 3 and 4. The first two hypotheses relate to individuallevel differences work-family reconciliation whereas the last two hypotheses relate to differences between groups of parents. In both cases I first entered the country-level characteristics, testing the direct effects (Models 2 and 4) and then estimated separate models for each interaction effect (Models 3a through $3 \mathrm{c}$ for the first set of hypotheses and Models 5a and $5 \mathrm{~b}$ for the second set).

\section{Results}

\subsection{Descriptive Analyses}

Table 1 presents the descriptive statistics of the individual-level variables and shows no remarkable results, except for the high proportion of women in the sample (which can be attributed to the construction of the sample). The country-level variables are shown in Table 2. Countries did not only differ in the average parent-child time (which varied between an average of $5.82 \mathrm{~h}$ per day in Luxembourg and $2.79 \mathrm{~h}$ in Belgium), but their standard deviations varied as well. The standard deviations were highest in Luxembourg and the Netherlands and lowest in Belgium and Portugal. The countries also varied greatly in their reconciliation policies, norms, the prevalence of part-time work, and earnings. Public spending on families was relatively high in the Continental countries

\footnotetext{
2 The multi-level models that were run are random effects models that are based on the assumption that the effects are distributed normally. Although the reason to test random effects models was theoretical (I was particularly interested in the country-level effects, the cross-level interactions and random slopes depending on countries), I performed a Hausman-test to check whether I violated the assumptions about the distributions of the random effects. For each model (i.e., Model 1 through 3d) I ran a fixed effects model and the Hausman tests confirmed the null-hypothesis that the differences in the coefficients were not systematic. Therefore, we can assume that the random effects models provided us with consistent estimations of the coefficients.
} 


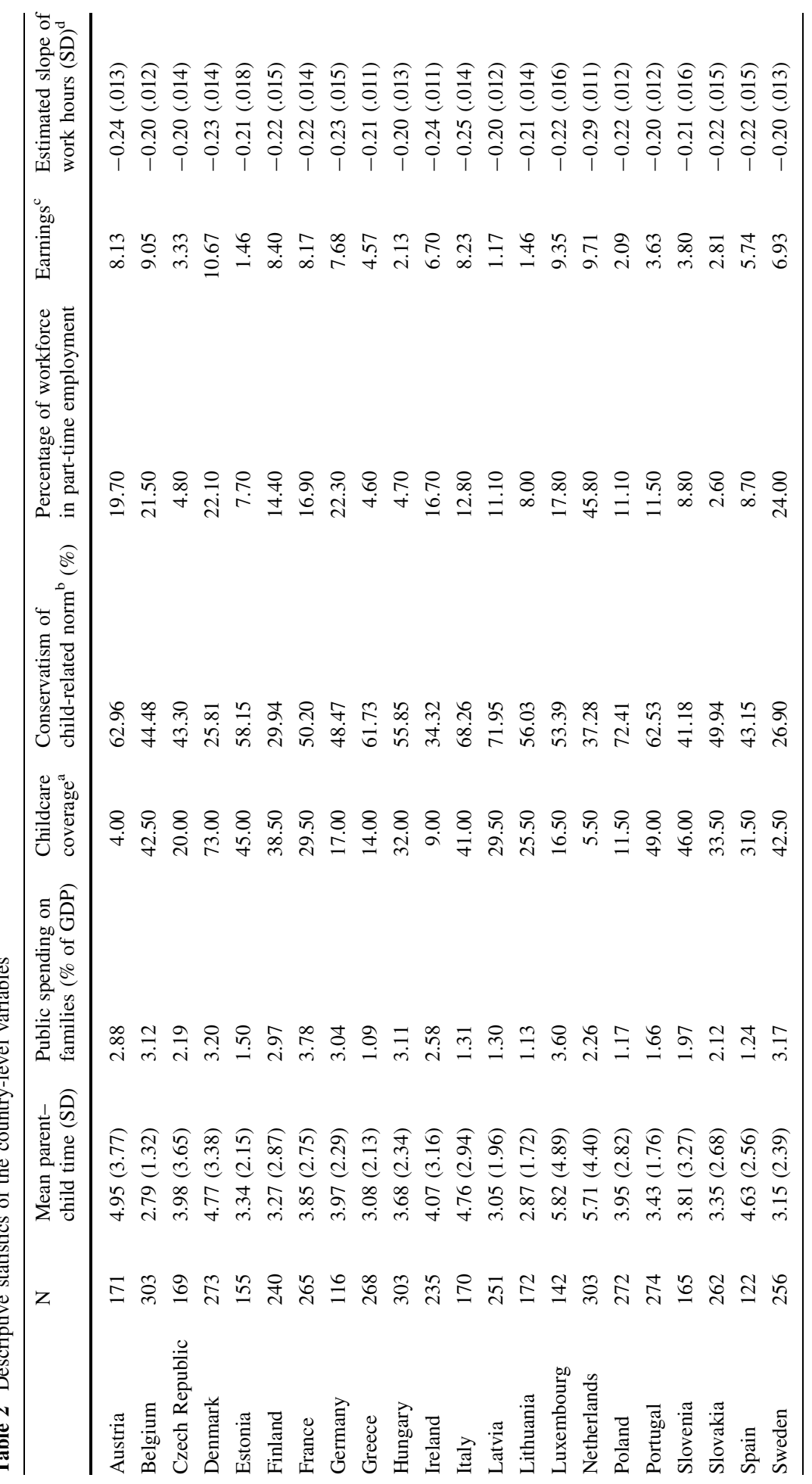




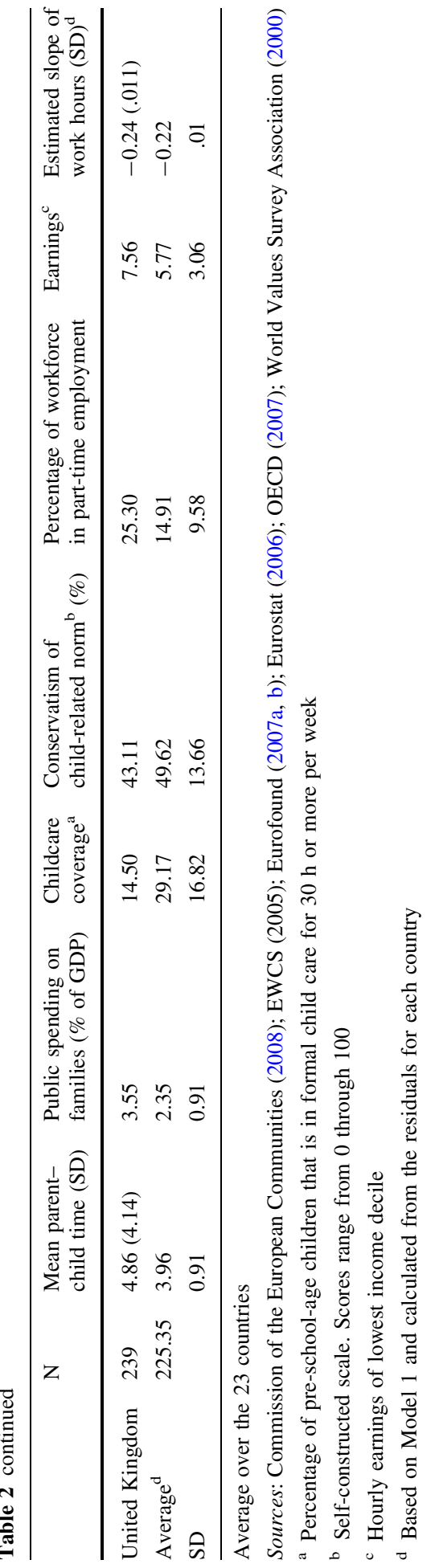


and the UK and lowest in the Southern and Eastern European countries. Child care coverage varied between $49 \%$ in Portugal and $4 \%$ in Austria, with Denmark as an extreme outlier $(73 \%)$. The data showed that parenthood ideologies were strongest in Southern European countries and weaker in the Scandinavian countries and the Netherlands. In most countries the percentage of the workforce in part-time work was between 10 and 20\% with relatively low percentages in Eastern European countries, and the highest percentage in the Netherlands (45.80\%). The Eastern European countries also ranked low with regard to the hourly earnings of the lowest income decile in PPS, the Southern and Continental countries took a middle position, and the Scandinavian countries ranked highest.

The final column of Table 2 lists the estimates of the country-specific slopes of work hours that were derived from Model 1. The results show that the association between work hours and parent-child time is negative in each country and that the slopes are very close to the overall mean. The negative association is strongest in the Netherlands, followed by Italy and Ireland. Sweden, Hungary, and Belgium rank lowest. In the Netherlands one additional work hour corresponds with $(-.288 \times 60=) 17$ min less parent-child time, whereas this decrease is $(-.195 \times 60=) 12 \mathrm{~min}$ in Sweden. Whereas this difference seems relatively small, it amounts to $1 \mathrm{~h}$ and 40 min per week when we would compare parents with a 20 - and 40-hour workweek.

\subsection{Multilevel Models}

The hypotheses were tested using multilevel modeling. In the first step the intercept-only model was estimated. The Intra Class Coefficient (ICC) was 0.072 implying that $7.2 \%$ of the variance of parent-child time lay on the country-level. In the second step the individual level variables were added to the model (results not reported). The intercept of parent-child time was allowed to vary randomly in this model, as well as in the subsequent models. Women appeared to spend more time with their children than men, and parent-child time decreased with the age of the youngest child. The number of children and the parent's educational level did not have an effect. The number of paid work hours, the main independent variable, was negatively associated with parent-child time $(\beta$ : $-.023, p=.000)$. This confirmed the 'Base Hypothesis'. In the third step, I tested whether the coefficient of work hours varied across countries by estimating a model with a random coefficient for work hours. This model (Model 1) is presented in Table 3. The improvement in the model fit as compared to the model with a fixed coefficient was significant (difference in $-2 \mathrm{LL}=45.291, d f=1, p=.000$ ), suggesting that there were indeed cross-national differences in the effect of work hours.

Exactly why the coefficient of work hours varied between countries was analyzed in the subsequent models. In the fourth step of the analysis the country-level variables were included in the model. The models testing the effects of public spending, child care coverage, and norms are presented in Model 2a (Table 3) and the results of the effects of part-time work and earnings are shown in Model 3a (Table 4). Model 2a showed that parents spent more time with their children in countries with higher public spending on families $(p=.024)$. The countries' child care coverage and parenthood ideology were not associated with parent-child time (with $p$-values of respectively .480 and .182). Model 3a showed that parent-child time was higher in countries where the average hourly earnings of the lowest income decile were higher $(p=.037)$. Parent-child time did not depend on the prevalence of part-time work however $(p=.485)$. 


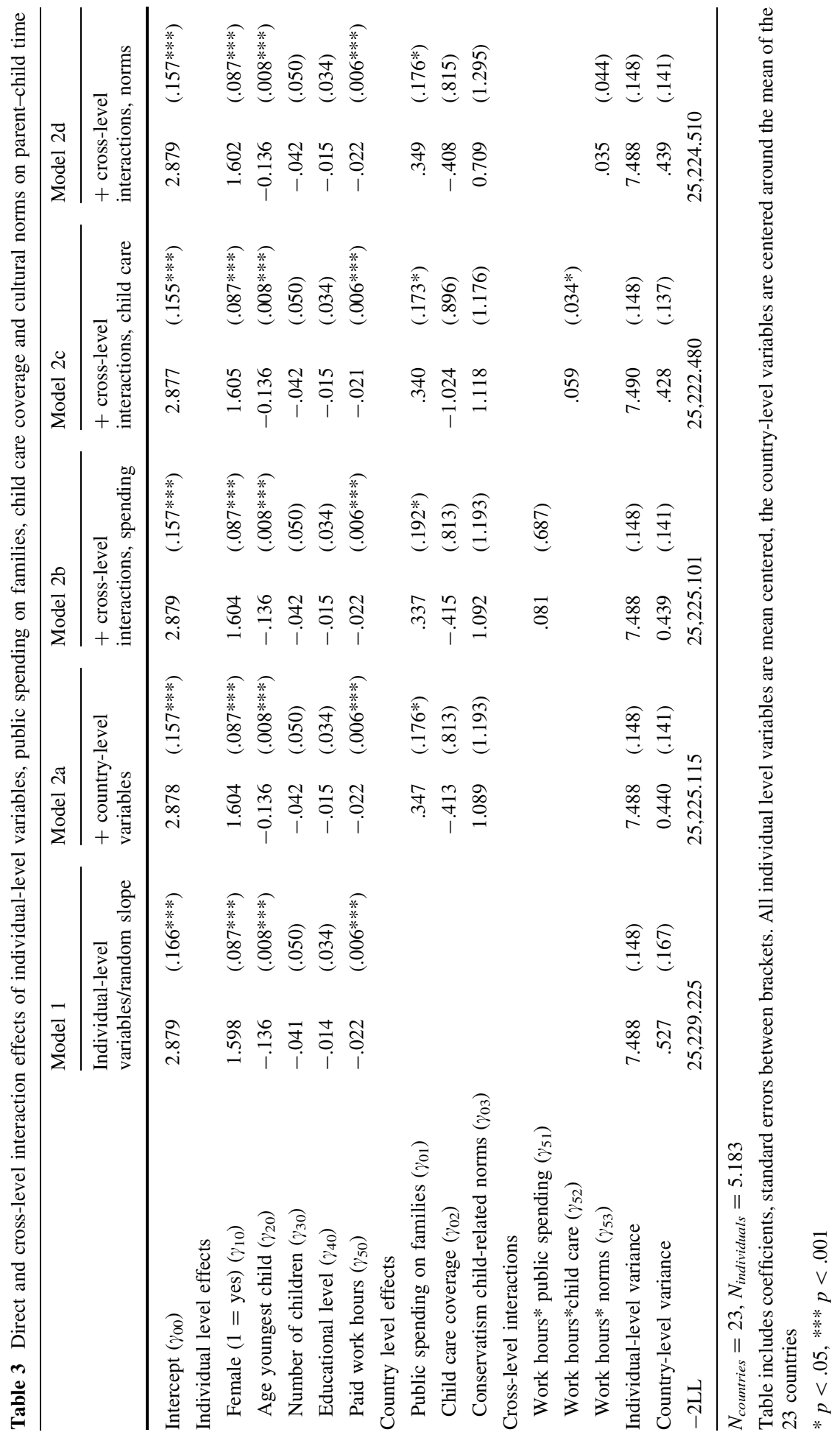




\subsubsection{Cross-Level Interactions}

In the next step the cross-level interactions were included in the models (Model 2b through 2d for the first set of hypotheses and Model $3 \mathrm{~b}$ and $3 \mathrm{c}$ for the second set). The results with regard to Hypothesis 1 showed that the interaction between public spending on families and work hours was nonsignificant (Model 2b). The level of child care coverage (Model 2c) did seem to condition the association between work hours and parent-child time however $\left(\gamma_{52}=.059\right.$, $p=.04)$. The positive coefficient implies that the negative effect of work hours on parentchild time became weaker when child care coverage increased. For example, in Denmark, with a child care coverage of $73 \%$, the difference in parent-child time between a parent who worked 20 and $50 \mathrm{~h}$ per week was $1.10 \mathrm{~h}$ a day, while the same difference in work hours results in a difference of $1.48 \mathrm{~h}$ a day of parent-child time in Austria (with a child care coverage rate of $4 \%$ ). Thus, the interaction effect between work hours and child care coverage was small but existent. Model $2 \mathrm{~d}$ showed that the child-related norms did not condition the effect of work hours. Summarizing, the hypotheses regarding the reconciliation of work and family demands received partial support. The association between working and parent-child time was indeed weaker in countries where former child care was more widely available, but financial government support and cultural norms did not reduce the effects of work hours.

The models testing the second set of hypotheses (Table 4) showed that although the prevalence of part-time work did not yield a direct effect in Model 3a, the effect of work hours was indeed stronger in countries where a larger percentage of the workforce is in part-time employment (Model 3b, $\gamma_{54}=-.192, p=.000$ ). For example, in the Netherlands, with a part-time percentage of 45.80 , parents who worked $20 \mathrm{~h}$ per week spent $2.39 \mathrm{~h}$ more a day with their children than parents who worked $50 \mathrm{~h}$ per week. This difference was $.10 \mathrm{~h}$ in Slovakia, where the part-time rate was $4 \%$. These findings are in line with the Hypothesis 3. Finally, Model $3 \mathrm{~b}$ showed that the interaction between work hours and hourly earnings had a negative and significant effect $\left(\gamma_{55}=-.005, p=.006\right)$, which suggests that the negative effect of work hours was stronger in countries where earnings were higher. In other words, parents in Denmark, the country with the highest earnings (10.67 PPS), the difference in parent-child time between parents working 20 and $50 \mathrm{~h}$ was $1.36 \mathrm{~h}$ a day, whereas this difference was $.57 \mathrm{~h}$ a day in Latvia where earnings are lowest (1.17 PPS). Summarizing, both Hypothesis 3 and 4 were supported by the data.

In order to check whether the skewness of the dependent variable affected the results, I ran Models 1 through $3 \mathrm{~d}$ on a transformed dependent variable. This variable was created with Stata's lnskew0-command that reduced the skewness to 0. There were no major differences in the results, with one exception. The $p$-value of the cross-level interaction between child care coverage and work hours changed from 0.04 (in the old model) to 0.05 (in the new model). It is therefore important to interpret this effect with additional care.

\subsubsection{Gender Differences}

Because previous research showed that men and women differ greatly with regard to workto-family effects and that it is mostly mothers who adjust their work demands to match their family responsibilities (e.g., Becker and Moen 1999; Bielby 1992; England and Farkas 1986; Maume 2008), additional analyses were performed to check whether our results apply to both genders (results not reported). Separate models for the fathers and mothers in the sample were analyzed. The results with regard to the first set of hypotheses were very similar for men and women. In contrast, Hypotheses 3 and 4 indeed seemed to apply mostly to the women in the sample. 


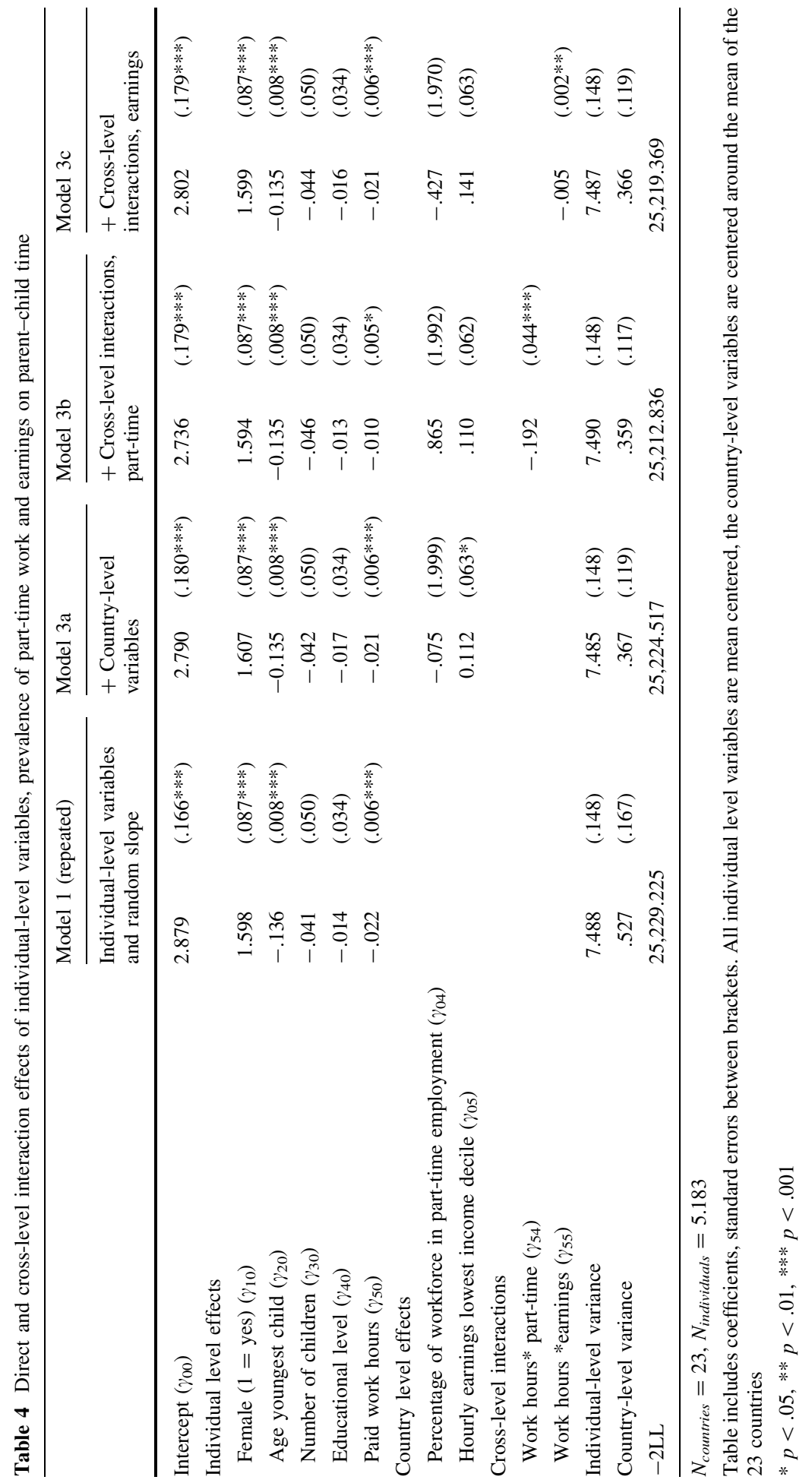




\section{Discussion}

Many studies investigated how parental work demands affect the time parents spend with their children, but the national context has seldom been taken into account. Yet, families function within a country's specific institutional and cultural structures and this context may influence parents' options when combining work and family demands. The current study examined whether the association between parental work hours and parent- child time varied across European countries and aimed to explain any variability on the basis of country characteristics.

Multilevel analyses on 5,183 employed parents with minor children from 23 European countries (the EU25 minus Cyprus and Malta) led to two main conclusions. First, the association between parental work hours and the time parents spent with their children indeed varied across countries. The general assumption that work hours cut into family time does therefore not hold equally in all countries. The deviations from the average slope were moderate though. Second, the results suggested that these cross-national differences were mainly attributed to differences in the opportunities to reduce one's work hours. The differences between parents who worked short and long hours were larger in countries where part-time work was more prevalent and earnings were higher. This suggests that parents in these countries have more opportunities to choose a work arrangement that fits their family needs and preferences: Those parents who want to spend a lot of time with their children are able to take a part-time job, whereas those who do have a stronger focus on their career are able to work longer hours. In countries where parents have a lesser say in their work hours the differences may be smaller because strongly involved parents who cannot reduce their hours maximize parent-child time in other ways (e.g., by spending less time in individual sport activities). Gauthier et al. (2004) explained the divergence in the parent-child time of employed and nonemployed mothers in the last decades on the basis of a similar mechanism. This study's finding that access to part-time work is mainly relevant for women is in line with previous research that found that women are more likely to adjust their work in such a way that family life is accommodated (e.g. Bielby 1992; Bianchi et al. 2006; England and Farkas 1986; Maume 2008).

In addition to studying the reduction of work demands as a possible work-family strategy, I studied whether opportunities to reconcile work and family demands conditioned the impact of paid work. The level of public spending on families and cultural norms did not account for the cross-national differences, but the level of child care coverage did reduce the strength of the association between of work hours and parent-child time. This moderating effect supports Bianchi's (2000) argument that research on the impact of parental work on parent-child time should take into account that children are not always available. When children are in child care for a substantial part of the week, lower work hours will not automatically imply that additional time is allocated to the children. This study suggests that parents spent this time in other activities, such as community work or the care for their own parents. Nonetheless, because the cross-level effect of child care did not appear to be very robust when we reduced the skewness of the measure for parentchild time and the highest-level sample size of the current study was relatively low (Maas and Hox 2005), the results with regard to child care coverage should be interpreted with care.

The lack of evidence for moderating effects of public spending and cultural norms on the association between work hours and parent-child time may indicate that high work and family demands are simply irreconcilable. There are at least two alternative explanations however. First, support and cultural norms in the direct context of the family (i.e., the 
workplace, friends, and family) may be more salient for the reconciliation of work and family than government support that is relatively distant. On a similar topic, Teachman and Crowder (2002) argued that criteria other than the geographic area, such as membership of certain social groups, determine what constitutes a relevant context. Second, it is possible that this study did not consider the appropriate indicators. With regard to the institutional context, public spending and child care coverage were included, but naturally there exist alternative indicators such as the type of welfare state, leave arrangements, the starting age in school, and the quality of child care. It could also be necessary to make a specific distinction between policies that are directed at one- and dual-earner families (Abendroth et al. 2009). Similarly, this study may not have taken the appropriate cultural norms into account. The importance parents attach to protecting family life from work encroachments was measured only indirectly, based on statements on the centrality of children and attitudes with regard to the harmful effects of maternal employment.

A remarkable finding of the current paper is that, with the exception of public spending, none of the country characteristics yielded a direct effect on parent-child time. This finding is relevant from both a theoretical and a methodological point of view. First, it suggests that the context is relevant because it shapes the conditions in which employed parents act. Relatively distant institutions do not seem to free or inhibit parent-child time directly; instead they appear to set the boundaries that determine which work-family strategies are most attractive and effective. Second, these findings prove the value of going beyond a descriptive comparison of countries and actually testing the effects of country-level characteristics and cross-level effects in multilevel analysis. Nonetheless, the exact pathways that connect country-level institutions to individual behavior still need further examination before we can conclude that their influence is limited. Policies and norms may influence parent-child time via work hours. For example, higher hourly wages may both increase or decrease work hours (Gershuny 2000). Moreover, it is important to acknowledge that country characteristics are interrelated. For example, Jones and Brayfield (1997) speculated that a country's family policies may influence this country's cultural norms. Future research could examine path models in order to increase insight in the specific mechanisms.

Recently, Sayer and Gornick (forthcoming) published a study that compared the work hour/parent-child association across nine Western countries by contrasting the estimated mean time parents in these countries and employment categories spent with their children. The results from this multilevel analysis are partly in line with their interpretations. With regard to "the buffer mechanism", the current study corroborates that the relatively high child care coverage in France, Norway, Sweden, and Slovenia is likely to account for the moderate effects of work hours on parent-child time. With respect to the selection effects, Sayer and Gornick set this possibility aside by arguing that higher educated women are strongly involved in their job and their children's lives. Yet, I controlled for educational level and still found that access to part-time work moderated the association between work hours and parent-child time. As Australia and the UK are both countries with relatively high female part-time rates (OECD 2010), this particular effect could explain why Sayer and Gornick found relatively strong effects of work hours in these countries. This does not, however, explain the large effect in the US and the weak effect they found in the Netherlands.

The case of the Netherlands brings us to the most remarkable discrepancy between the current study and Sayer and Gornick. In the current study the Netherlands stood out as a country with a strong association between work hours and parent-child time, whereas this association was relatively weak in Sayer and Gornick's study. It is important to note however, that Sayer and Gornick were only able to compare non-employed mothers and mothers who worked 15-30 h. Moreover, as Sayer and Gornick showed themselves, in 
some countries it was employment status per se that mattered whereas it was the exact number of work hours in other countries (p.15). Thus, the gap in parent-child time between relatively involved parents who work short and long hours may be relatively large in the Netherlands, while the gap between employed and non-employed parents is relatively small. The results may also differ because the range in parent-child time is narrower in this study as compared to Sayer and Gornick. Nevertheless, in the specific case of the Netherlands the selectivity of the sample (employed parents who were involved with their children on a daily basis) may not be problematic as most Dutch parents are in paid employment (The Netherlands Institute for Social Research [SCP] 2011a) and are relatively involved with their children (Bianchi et al. 2006). For example, in 2005 Dutch parents had dinner with their children on an average of almost six out of the seven nights of the week (SCP 2011b: 108).

On a more general level, the possibility that differences in the findings are the result of differences in the data is very plausible and it is important to acknowledge that the measure of parent-child time in the EWCS data is limited. The respondents in the EWCS were not asked directly how much time they spent with their children on a daily basis and I therefore had to exclude those respondents who indicated that they spent less than an hour per day. Time-diary data could provide more valid and reliable information on parent-child time. Measuring time use on week and weekend days would also enable us to take into account that parents who are busy during the week might compensate during weekends. Unfortunately, the number of countries in the MTUS data set was too limited to employ multilevel analyses and because the main aim of the study was to test the moderating effects of country characteristics I chose to use the EWCS data that covered 23 countries. A final limitation of this study is that it may have suffered from problems of equivalence that are common in cross-national research (Jones and Brayfield 1997). Questions may have been interpreted differently across countries (e.g., "caring for and educating your children" may mean something different in Italian than in Sweden). Similarly, country data were not always collected in the same way. For example, some countries included data on tax measures in the public spending measure whereas others did not.

Despite this study's limitations, its worth lies in its systematic examination of moderating effect of country characteristics on the individual-level association between work hours and parent-child time. Also, by excluding the parents who are involved with their children on a less than daily basis, I most likely underestimated (rather than overestimated) the selection effects. Nevertheless, the possibility that we exclude a large proportion of the parents in other countries should be minimized and the recent and ongoing extensions of the MTUS data and the increasing availability of "with whom" data offer future possibilities to replicate these analyses using time use data for a wider sample. Also, the EU actively monitors developments in the member states, for example with regard to the Barcelona targets on child care provision, and it is therefore likely that more information on the new EU and candidate countries will become available soon, which would make it possible to test the model on a larger sample of countries as well.

Fathers and mothers coordinate family life together and work-family strategies are often decided upon together (Becker and Moen 1999). Moreover, a parent can also be influenced by his or her partner's work hours through the level of specialization and distribution of bargaining power within the couple (Hook 2006). In this study I could not account for the influence of the partner however, as there were no couple data available. This could have distorted the results, especially if parents compensated for each other more in some countries than in others. There is some tentative evidence that this may be the case. Prior research has found that countries can enhance specialization through social policies such as 
parental leave (Hook 2006: 655; Gornick and Meyers 2003) and Fuwa (2004) demonstrated that time availability reduces women's share in unpaid labor more in countries that are more egalitarian attitudes. Future research could further explore this.

Another interesting direction for future research would be to extend the scope and examine the effects on child well-being. Although the UNICEF report (2007) suggests that children do better in countries where parents spend more time with their children, parentchild time was considered as an indicator of child well-being and not as a predictor. Moreover, it is interesting that child well-being is not necessarily higher in countries where children are regarded as more central (Treas and Widmer 2000). Further research on the interconnectedness of country characteristics, parent-child time, and outcomes for children could create relevant knowledge that could serve to improve child well-being.

Concluding, this study demonstrates that it is important to consider the national context when studying work-to-family effects. Parents, and mothers in particular, actively protect family life from work encroachments and the extent to which they succeed in doing so depends on the institutional context. On the one hand, this implies that studies comparing work-to-family effects across different countries should be done so with care. On the other hand, this offers interesting new avenues for future research that could potentially help countries to develop policies facilitating parents in reconciling work and family life.

Open Access This article is distributed under the terms of the Creative Commons Attribution Noncommercial License which permits any noncommercial use, distribution, and reproduction in any medium, provided the original author(s) and source are credited.

\section{References}

Abendroth, A. K., Van der Lippe, T. \& Maas, I. (2009). Social support and work hours of employed mothers in Europe. The relevance of the state, the workplace, and the family. Paper presented at the community, work, and family conference, Utrecht, The Netherlands, April 16-18, 2009.

Becker, P. E., \& Moen, P. (1999). Scaling back: Dual-earner couples' work-family strategies. Journal of Marriage and the Family, 61, 995-1007.

Bianchi, S. M. (2000). Maternal employment and time with children: Dramatic change or surprising continuity? Demography, 37, 401-414.

Bianchi, S. M., Robinson, J. P., \& Milkie, M. A. (2006). Changing rhythms of American family life. New York: Russell Sage Foundation Publications.

Bielby, D. D. (1992). Commitment to work and family. Annual Review of Sociology, 18, 281-302.

Bittman, M. (2009). The balance between parents' time and money in raising children-A preliminary study of outcomes of alternative policy regimes. Paper presented at the IATUR conference, Lüneburg, Germany, September 23-25, 2009.

Commission of the European Communities. (2008). Implementation of the Barcelona Objectives concerning childcare facilities for pre-school-age children. Commission staff working document ICOM (2008) $598\}$.

Coverman, S. (1985). Explaining husband's participation in domestic labor. Sociological Quarterly, 26, 81-97.

Crouter, A. C., Bumpus, M. F., Head, M. R., \& McHale, S. M. (2001). Implications of overwork and overload for the quality of men's family relationships. Journal of Marriage and Family, 63, 404-416.

Den Dulk, L., \& Van Doorne-Huiskens, A. (2007). Social policy in Europe: Its impact on family and work. In R. Crompton, S. Lewis, \& C. Lyonette (Eds.), Women, men, work and family in Europe. UK: Palgrave Macmillan.

Eby, L. T., Casper, W. J., Lockwood, A., Bordeaux, C., \& Brinley, A. (2005). Work and family research in IO/OB: Content analysis and review of the literature (1980-2002). Journal of Vocational Behavior, 66, 124-197.

England, P., \& Farkas, G. (1986). Households, employment, and gender: A social, economic, and demographic view. New York: Aldine.

Esping-Andersen, G. (1999). Foundations of postindustrial economies. Oxford: Oxford University Press. 
Eurofound. (2007a). Fourth European working conditions survey. Dublin: European Foundation for the Improvement of Living and Working Conditions.

Eurofound. (2007b). Quality report of the 4th European working conditions survey. Dublin: European Foundation for the Improvement of Living and Working Conditions.

Eurostat. (2006). Statistics in focus. Earnings disparities across European countries and regions. European Communities.

Female power. (2010). The Economist, 167, 49-51.

Foundation, Nuffield. (2009). Time trends in parenting and outcomes for young people. London: Nuffield Foundation.

Fuwa, M. (2004). Macro-level gender inequality and the division of household labor in 22 countries. American Sociological Review, 69, 751-767.

Gauthier, A. H., Smeeding, T., \& Furstenberg, F. F., Jr. (2004). Are parents investing less time in children? Trends in selected industrialized countries. Population and Development Review, 30, 647-671.

Geschuny, J. (2000). Changing times: Work and leisure in postindustrial society. Oxford: Oxford University Press.

Gornick, J. C., \& Meyers, M. (2003). Families that work: Policies for reconciling parenthood and employment. New York: Russell Sage Foundation.

Greenhaus, J. H., \& Beutell, N. J. (1985). Sources of conflict between work and family roles. Academy of Management Review, 10, 76-88.

Greenhaus, J. H., \& Powell, G. N. (2006). When work and family are allies: A theory of work-family enrichment. Academy of Management Review, 31, 72-92.

Hays, S. (1996). The cultural contradictions of motherhood. New Haven: Yale University Press.

Hakim, C. (2002). Lifestyle preferences as determinants of women's differentiated labor market careers. Work and Occupations, 29, 428-459.

Hook, J. L. (2006). Care in context: Men's unpaid work in 20 countries, 1965-2003. American Sociological Review, 71, 639-660.

Jones, R. K., \& Brayfield, A. (1997). Life's greatest joy? European attitudes toward the centrality of children. Social Forces, 75, 1239-1269.

Maas, C. J. M., \& Hox, J. J. (2005). Sufficient sample sizes for multilevel modelling. Methodology, 1, 86-92.

Maume, D. J. (2008). Gender differences in providing urgent childcare among dual-earner parents. Social Forces, 87, 273-297.

Moen, P., \& Wethington, E. (1992). The concept of family adaptive strategies. Annual Review of Sociology, 18, 233-251.

Nock, S. L., \& Kingston, P. W. (1988). Time with children: The impact of couples' work-time commitments. Social Forces, 67, 59-85.

Organization for Economic Cooperation and Development (OECD). (2007). Babies and Bosses. Reconciling work and family life. A synthesis of findings for OECD countries. OECD.

Organization for Economic Cooperation and Development (OECD) Family Database. (2008). Chart PF1.1. Public spending on family benefits. Available at: http://www.OECD,.org/dataOECD,/55/58/3896 8865.xls. Accessed 8 October 2009.

Organization for Economic Coorperation and Development (OECD). (2010). Labour market statistics by seb and age: indicators. OECD employment and labour market statistics database (copyright), http://dx.doi.org.10.1787/data-00310-en>.

Plantenga, J., \& Remery. R. (2005). Reconciliation of work and private life: A comparative review of thirty European countries. Office for official publications of the European communities.

Poelmans, S. A. Y., \& Caligiuri, P. (Eds.). (2008). Harmonzing work, family, and personal life. From policy to practice. England: Cambridge University Press.

Presser, H. B. (1994). Employment schedules among dual-earner spouses and the division of household labor by gender. American Sociological Review, 59, 348-356.

Reynolds, J. (2003). You can't always get the hours you want: Mismatches between actual and preferred work hours in the U.S. Social Forces, 81, 1171-1199.

Roeters, A., Van der Lippe, T., \& Kluwer, E. S. (2010). Work characteristics and parent-child relationship quality: The mediating role of temporal involvement. Journal of Marriage and Family, 72, 1317-1328.

Sayer, L. C., \& Gornick, J. C. (forthcoming). Cross-national variation in the influence of employment hours on child care time. European Sociological Review. doi:10.1093/esr/jcr008.

Sayer, L. C., Gauthier, A. H., \& Furstenberg, F. F., Jr. (2004). Educational differences in parents' time with children: Cross-national variations. Journal of Marriage and Family, 66, 1152-1169.

Stone, P. J. (1972). Child care in twelve countries. In A. Szalai (Ed.), The use of time: Daily activities of urban and suburban populations in twelve countries. The Hague: Mouton. 
Teachman, J., \& Crowder, K. (2002). Multilevel models in family research: Some conceptual and methodological issues. Journal of Marriage and the Family, 64, 280-294.

The Netherlands' Institute for Social Research/SCP. (2011a). Emancipatiemonitor 2010 [Emancipation monitor 2010]. Den Haag: SCP.

The Netherlands' Institute for Social Research/SCP. (2011b). Gezinsrapport 2011 [Family report 2011]. Den Haag: SCP.

Treas, J., \& Widmer, E. D. (2000). Married women's employment over the life course: Attitudes in crossnational perspective. Social Forces, 78, 1409-1436.

UNICEF. (2007). Child poverty in perspective: An overview of child well-being in rich countries. Innocenti Research Centre Report card No. 7. UNICEF.

Wall, K. (2007). Main patterns in attitudes to the articulation between work and family Life: A crossnational analysis. In R. Crompton, S. Lewis, \& C. Lyonette (Eds.), Women, men, work and family in Europe. Basingstoke: Palgrave Macmillan.

World Values Survey Association. (2000). 2000 official data file v.20090914. World values survey association. Available at http://www.worldvaluessurvey.org. Accessed 6 October 2009. 